\title{
ANTIMICROBIAL ACTIVITIES OF SOME MEDICINAL PLANTS OF KASHMIR HIMALAYA AS BIORESOURCES TO OVERCOME THE CHALLENGES OF ANTIBIOTIC RESISTANCE
}

\author{
Aadil Hussain* and Suchi Modi \\ Department of Botany, School of Biological Sciences \\ Rabindranath Tagore University, Madhya Pradesh, India
}

\begin{abstract}
Through the realization of the continuous erosion of traditional knowledge of plants used for medicine in the past and the renewed interest at the present time, a need existed to review this valuable knowledge of medicinal plants with the purpose of developing medicinal plants sectors across the different states in India. Our major objectives therefore were to explore the potential in medicinal plants resources, to understand the challenges and opportunities with the medicinal plants sector, and also to suggest recommendations based upon the present state of knowledge for the establishment and smooth functioning of the medicinal plants sector along with improving the living standards of the underprivileged communities. The review reveals that State of Kashmir harbours a rich diversity of valuable medicinal plants, and attempts are being made at different levels for sustainable utilization of this resource in order to develop the medicinal plants sector. Antimicrobial activity refers to the process of killing or inhibiting the growth of microbes. Various antimicrobial agents are used for this purpose. Antimicrobial may be anti-bacterial, anti-fungal or antiviral. Antimicrobial activity can be defined as a collective term for all active principles (agents) that inhibit the growth of bacteria, prevent the formation of microbial colonies, and may destroy microorganisms. In the field of antimicrobial finish, many common terms are used including antibacterial, bactericidal, bacteriostatic, fungicidal, fungistatic, biocidal, and biostatic. Antimicrobial activity refers to a situation where an active agent has a negative effect on the vitality of microorganisms.In present study we studied Antimicrobial Activities of Some Medicinal Plants of Kashmir Himalaya
\end{abstract}

Keywords: Antimicrobial, Kashmir Valley, Traditional Knowlede, Antibiotic resistance.

\section{INTRODUCTION}

The medicinal properties of plant species have made an outstanding contribution in the origin and evolution of many traditional herbal therapies. These traditional Knowledge systems have started to disappear with the passage of time due to scarcity of written documents and relatively low income in these traditions. Over the past few Years, however, the medicinal plants have regained a wide recognition due to an escalating faith in herbal medicine in view of its lesser side effects compared to allopathic medicine in addition the necessity of meeting the requirements of medicine for an increasing human population. About $70-80 \%$ people around the World rely on medicinal plants for major health care (Kong J. Met al. 2003).
Through the realization of the continuous erosion of traditional knowledge of plants used for medicine in the past and the renewed interest at the present time, a need existed to review this valuable knowledge of medicinal plants with the purpose of developing medicinal plants sectors across the different states in India. Our major objectives therefore were to explore the potential in medicinal plants resources, to understand the challenges and opportunities with the medicinal plants sector, and also to suggest recommendations based upon the present state of knowledge for the establishment and smooth functioning of the medicinal plants sector along with improving the living standards of the underprivileged communities. The review reveals that State of Kashmir

*Corresponding author: loneaadil46@gmail.com 
harbours a rich diversity of valuable medicinal plants, and attempts are being made at different levels for sustainable utilization of this resource in order to develop the medicinal plants sector. (Kaul M. K. 1997.) Information on the propagation of medicinal plants is available for less than $10 \%$ and Agro-technology is available only for $1 \%$ of the total known plants globally. This trend shows that developing agro-technology should be one of the thrust areas for research. Furthermore, in order to meet the escalating demand of medicinal plants, Farming of these plant species is imperative. Apart from meeting the present demand, Farming may conserve the wild genetic diversity of medicinal plants. Farming permits the production of uniform material, from which standardized products can be consistently obtained. (Chatterjee, S. K. 2001)Cultivation also permits better species identification, improved quality control, and increased prospects for genetic improvements. Selection of planting material for large-scale farming is also an important task. The planting material therefore should be of good quality, rich in active ingredients, pest- and 186 disease-resistant and environmental tolerant. For the large scale farming, one has to find out whether monoculture is the right way to cultivate all medicinal plants or one has to promote polyculture model for better production of medicinal plants. (Bates, G. H 1933).

The problem of antibiotic resistance, which has limited the use of cheap and old antibiotics, has necessitated the need for a continued search for new antimicrobial compounds. Understanding the mechanisms of resistance is important in the development of strategies to solving the problem. Active efflux of drugs, alteration of target sites and enzymatic degradations are the strategies by which pathogenic bacteria acquire or develop intrinsic resistance to antibiotics(Liu, B., \& Pop, M. 2009). Multi-drug resistance (MDR) pumps, capable of recognizing and expelling a variety of structurally unrelated compounds from the bacterial cell and conferring resistance to a wide range of antibiotics have since been characterized in many gram positive and gram negative pathogens like Staphylococcus aureus, Pseudomonas aeruginosa, Escherichia coli and, more recently, in mycobacterium. The ability of some chemical compounds (called MDR inhibitors or resistance modifying agents) to modify the resistance phenotype in bacteria by working synergistically with antibiotics in vitro has since been observed. The search for such compounds which can be combined with antibiotics in the treatment of drug resistant infections may be an alternative to overcoming the problem of resistance in bacteria. Crude extracts of medicinal plants stand out as veritable sources of potential resistance modifying agents (sDavies, J., \& Davies, D. 2010).

\section{STUDYAREA}

The state of Jammu \& Kashmir constitutes the Northern most extremity of India. Baramulla is one of the 22 districts in J\&K UT, situated at an average height of $1581 \mathrm{~m}$ above mean sea level (AMSL) and is spread over an area of 4191 sq. kms. It is bounded in the North by district Kupwara, in the South by districts of Budgam, Poonch and parts of Srinagar and in the East by Ladakh. Line of control lies in its West(Yousuf et al 2001).. The climate of the Baramulla district is of Mediterranean type with four distinct seasons viz. Spring (March May), summer (June - August), autumn (September- November) and winter (DecemberFebruary). The monthly mean temperature ranges from 0.030C in January to 30.10 C in July.

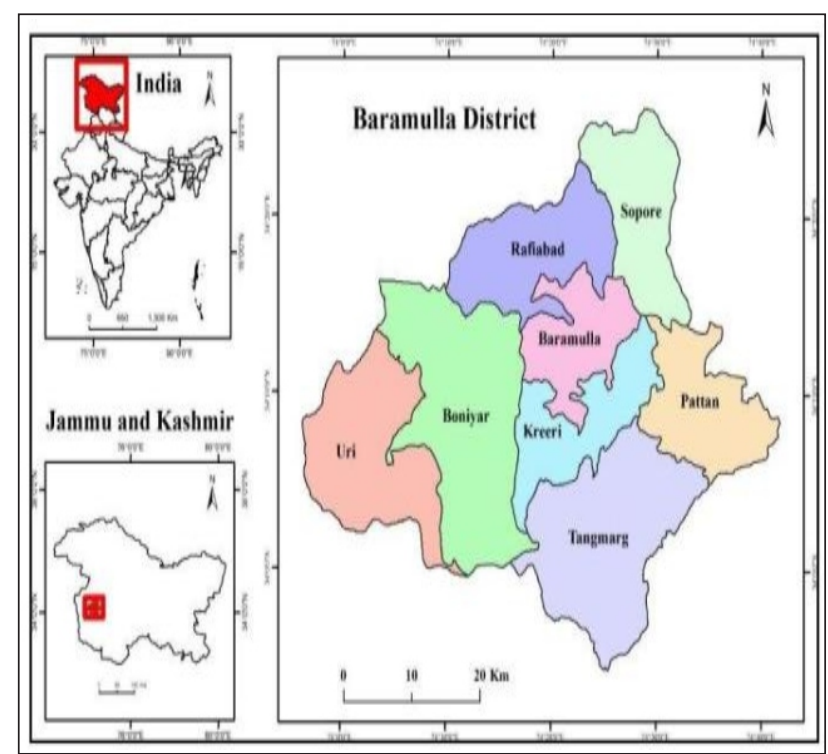

\section{MATERIALAND METHODS}

The whole plant material was collected from the study area by simple random technique. Fresh plant material was washed with distilled water to remove dust and other extraneous matter. The plant material was dried in the shade for preparation of plant extract.

1. The studay area was visited for the collection of plant material (Thymus linearsi, Malva neglecta, Dipcus inermis, and Urtica dioica ) using cutter and put into polythene bags.

2. The different parts of plants were used to prepare extracts for the study. The plants collected were washed with water to remove the soil and dust particles

3. The collected plant materials were sorted and sun shade dried in a room, free from moisture for 1520 days.

4. After 5-20 day the shade dried plants were further dried in an oven for 6 hours. 
5. The oven dried plants were crushed using mortar and pestle to form fine powder of it.

6. Equal amount/weights of fine powder of each plant (Thymus line, Malva neglecta, Dipcus inermis, and Urtica dioica) was dissolved in 50ml of methanol solvent in the falcon tube.

7. The tubes containing the solvent and plant material was continuously shaked on vortex. Shaking was done occasionally for about 7days.

8. The methanolic liquid was strained off in a beaker.

9. The methanolic extract was concentrated by evaporation

\section{Determination of anti-microbial activity}

Antimicrobial activity refers to the process of killing or inhibiting the growth of microbes. Various antimicrobial agents are used for this purpose. Antimicrobial may be antibacterial, anti-fungal or antiviral.

Antimicrobial activity can be defined as a collective term for all active principles (agents) that inhibit the growth of bacteria, prevent the formation of microbial colonies, and may destroy microorganisms. In the field of antimicrobial finish, many common terms are used including antibacterial, bactericidal, bacteriostatic, fungicidal, fungistatic, biocidal, and biostatic. Antimicrobial activity refers to a situation where an active agent has a negative effect on the vitality of microorganisms. A variety of laboratory methods can be used to evaluate or screen the in vitro antimicrobial activity of an extract or a pure compound. The most known and basic methods are the disk-diffusion, broth or agar dilution method and agar well diffusion method.

\section{Agar well diffusion method}

Antimicrobial activity of methanolic extracts of selected plants (Thymus lineris, Malva neglecta, Dipcus inermis, and Urtica dioica) was determined by agar well diffusion method according to National Committee for Clinical Laboratory Standards (NCCLS). Inoculums of bacterial culture (E. coli) to be tested were spread on nutrient agar plates with a sterile swab moistened with the bacterial suspension. Subsequently, wells of $8 \mathrm{~mm}$ diameter were punched into the agar medium and filled with required quantity of plant extract and allowed to diffuse at room temperature for $2 \mathrm{~h}$. The plates were then incubated in the upright position at $37^{\circ}$ for $24 \mathrm{~h}$. After incubation, the diameters of the growth inhibition zones were measured in mm.

\section{MATERIALS REQUIRED}

Beaker, measuring cylinder, pipit, Petriplates.

\section{Bacterial strain used}

Commonly used bacterial strain Escherichia coli (DH5 $\alpha$ )

\section{RESULTS}

The antimicrobial potential of the experimental plants (Thymus lineris, Malva neglecta, Dipcus inermis, and Urtica dioica) was evaluated according to their zone of inhibition against E.coli and the results (zone of inhibition) was compared with the activity of standard amplicillin (1.0mg/10ml of DD $\mathrm{H}_{2} \mathrm{O}$ ) the results revealed that all plant extract were having potent antimicrobial activity against E.coli strain. Methanol extract showed minimum zone of inhibition where as standard amplicillin showed maximum zone of inhibition.

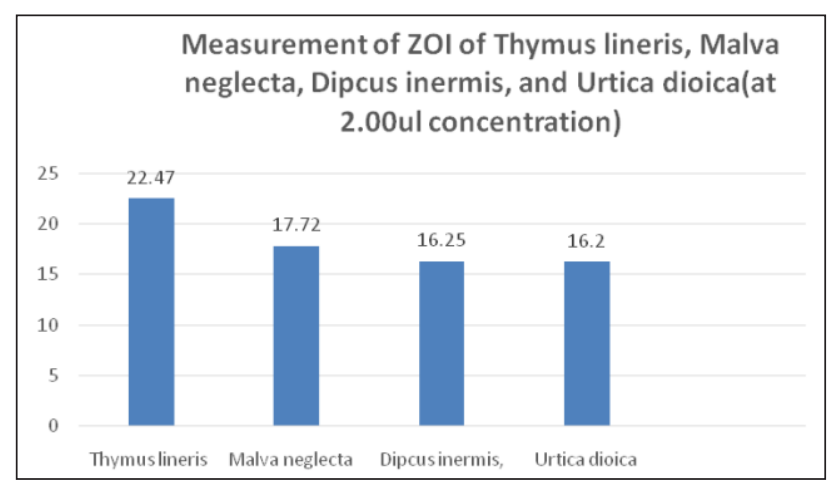

\section{DISCUSSIONAND CONCLUSION}

The presence of antibacterial substances in the higher plants is well established. The present study provides comprehensive report of antimicrobial activity of some medicinal plants of Kashmir Himalaya. Plants have provided a source of inspiration for novel drug compounds as plants derived medicines have made significant contribution towards human health. Phytomedicine can be used for the treatment of diseases as is done in case of Unani and Ayurvedic system of medicines or it can be the base for the development of a medicine, a natural blueprint for the development of a drug. Medicinal plants are part and package of human society to fighting against diseases from the dawn of civilization. Medicinal plants are rich sources of antimicrobial agents. Plants are used medicinally throughout the world and are the source of potential and powerful drugs. A wide range of medicinal parts The herbal products today indicate safety in distinction to the synthetics that are regarded as dangerous to human and environment. Due to the overuse of prescription antibiotics which can lead to the development of antibiotic-resistant strains of bacteria, many medical experts are taking a new look at natural, safe antibiotic alternatives. There are a number of natural herbal antibiotics that should be studied and keep on hand repeatedly. To battle against any kind of infection or illness, medicines prepared from the natural 
herbs can be used which are relatively inexpensive, and can be stored for a year or more at room temperature. The conventional medical establishment has recently warmed up to the immense potential of using herbal medicines for fighting infections. The number of natural substances that fight infection is surprising, and the research for discovering new such substances still continues. These natural substances either contain antibiotic properties in themselves, or provide to spur the production of the body's own protection mechanisms. Human beings have been using herbal medicines for more than 60,000 years! And those herbal medicines are still used by $80 \%$ of the world's population as their primary health care (statistic from the World Health Organisation). It has been estimated that in the developed countries like United States, herbal drugs constitute $25 \%$ of the total drugs, while in fast developing countries like China and India, the contribution is as much as $80 \% .3$ Herbal antibiotics have very complex nature(Cakilcioglu et al 2010).. These antibiotics are used for killing bacteria, cleanse the blood, strengthen the immune system, increase the mucous membrane tone and increase the functions of particular organ systems. Thus, instead of simply killing bacteria by using 'antibiotic' plants, they treat the imbalances of the whole body. In conclusion, the results confirmed the traditional use of the herb against antimicrobial diseases. These plants could act as a potential antimicrobial agent; however, further studies are required for them to be safely used in the control of disease and pests.

\section{SUMMARYAND CONCLUSION}

In this work, the antimicrobial of (Thymus linearis, Malva neglecta, Dipcus inermis, and Urtica dioica) were reported. All the plant extract showed anti microbial activity based on the measurement of zone of inhibition Based on the results, methanolic extract of thymus linearis showed the maximum antibacterial activity against the selected bacteria pathogens, In conclusion, the results confirmed the traditional use of the herb against antimicrobial diseases. These plants could act as a potential antimicrobial agent; however, further studies are required for them to be safely used in the control of disease and pests.

\section{REFERENCES}

1. Bates, G. H. (1933). The distribution and control of the great stinging nettle. Journal of the Ministry of Agriculture, 39, 912-22.

2. Cakilcioglu, U., \& Turkoglu, I. (2010). An ethnobotanical survey of medicinal plants in Sivrice (Elazığ Turkey). Journal of Ethnopharmacology, 132(1), 165-175.

3. Chatterjee, S. K. (2001, July). Cultivation of medicinal and aromatic plants in India-A commercial approach. In International Conference on Medicinal and Aromatic Plants. Possibilities and Limitations of Medicinal and Aromatic Plant 576 , 191-202.

4. Davies, J., \& Davies, D. (2010). Origins and evolution of antibiotic resistance. Microbiology and molecular biology reviews, 74(3), 417-433.

5. Kaul, M. K. (1997). Medicinal plants of Kashmir and Ladakh: temperate and cold arid Himalaya. Indus publishing.

6. Kong, J. M., Goh, N. K., Chia, L. S., \& Chia, T. F. (2003). Recent advances in traditional plant drugs and orchids. Acta Pharmacologica Sinica, 24(1), 7-21.

7. Liu, B., \& Pop, M. (2009). ARDB-antibiotic resistance genes database. Nucleic acids research, 37 ( 443-447.

8. Yousuf, J., Verma, R. K., \& Dar, H. (2012). Traditional plant based therapy among rural communities of some villages of Baramulla district (Jammu and Kashmir). Journal of phytology. 